\title{
Exploring Recurrent Respiratory Papillomatosis: A Mini-Review
} \author{
Massawe $^{3}$ \\ ${ }^{1}$ Department of Surgery-University of Dodoma, College of Health Sciences, Tanzania \\ ${ }^{2}$ Department of Otorhinolaryngology, Muhimbili National Hospital, Tanzania \\ ${ }^{3}$ Department of Otorhinolaryngology, Muhimbili University of Health and Allied Sciences, Tanzania
}

Zephania Saitabau Abraham ${ }^{1 *}$, Edwin Liyombo ${ }^{2}$, Aveline Aloyce Kahinga ${ }^{3}$, Daudi Ntunaguzi ${ }^{3}$ and Enica Richard

Submission: February 08, 2019; Published: February 19, 2019

*Corresponding author: Zephania Saitabau Abraham, Department of Surgery, University of Dodoma, College of Health Sciences, Tanzania

\begin{abstract}
Recurrent respiratory papillomatosis (RRP) is a term which has been used to describe Human papillomavirus (HPV) infection of the upper aerodigestive tract affecting both children and adults. It's mostly self-limited and with bimodal distribution pattern in children. The juvenile form develops in patients less than 20 years of age, but adult form develops after 20 years of age in those at their 3rd or 4th decades of life. Though the virus has affinity to any part of the upper aerodigestive tract, but it has much more propensity to the larynx. Most infections in children occur at birth during passage through the birth canals of contaminated mothers while in adults, HPV is transmitted sexually. Natural history of RRP has remained unpredictable ranging from mild attacks with spontaneous remissions to severe attacks manifested by its aggressiveness characterized by distal spread to the pulmonary tree and recurrent episodes which necessitate frequent surgical debulking. RRP usually present with nonspecific symptoms of airway involvement, including chronic cough, hoarseness, wheezing, stridor, and chronic dyspnea and thus commonly misdiagnosed. Recurrent attacks of RRP impair one's quality of life such as impaired academic performance and altered socioeconomic status in both children and adults due to social stigma which may be due to hoarseness of voice and/or tracheostomy. Although rare, RRP can undergo malignant transformation to squamous cell carcinoma. Such transformation has remained to be a topic of debate since it has been reported invariably. The aim of this review is thus to discuss various aspects of RRP..
\end{abstract}

Keywords: Recurrent; Respiratory; Papillomatosis

\section{Introduction}

Recurrent Respiratory Papillomatosis is a rare disease characterized by recurrent growth of benign papillomatous lesions in the respiratory tree of both adults and children with the exclusive aetiology being Human papillomavirus [1-4]. Such lesions may occur anywhere in the upper aerodigestive tract [5] though in most occasions affect the larynx and that's why some literatures describe such disease condition to be "Recurrent laryngeal papillomatosis". It has the tendency of afflicting both children and adults [6,7]. The average time from onset of the symptoms and diagnosis ranges from 1 to 8 years [4]. The papillomata can occur anywhere in the aerodigestive tract but most frequently in the larynx, affecting both children and adults [5]. Even though the disease is benign but may cause significant morbidity and mortality and an accompanied excess expenses incurred in treating the patient who usually undergo numerous episodes of surgical interventions that are preceded by frequent doctor visits for the same complaints. There are some reports showing the possibility of malignant transformation of RRP, but this has been invariably reported $[8,9]$. The estimated incidence of RRP is 2 per 100,000 in adults and 4 per 100,000 in children $[4,10]$. The prevalence of HPV infection has been increasing gradually in the female population where the estimated prevalence in women aged $14-59$ is $26.8 \%$, and that in women aged $20-24$ years is $45 \%$. As per the socioeconomic status, the incidence of RRP varies invariably where they are higher in groups with lower socio-economic status and low educational levels though no correlation has been found between socioeconomic status and the severity of RRP [11].

Executing management to patients with RRP has remained to be a challenge to Otorhinolaryngologists. There are promising surgical interventions coupled with several adjuvant therapies, but they will still remain to be palliative measures to such terrible disease [12-18]. Intraoperatively, surgeons have been facing challenge when it comes to voice preservation techniques during microlaryngeal surgery especially when repeated surgeries for the papillomatous lesions are to be 
performed. In developing countries where patients are living in sub-standards of life and with poor tendency of seeking health care, they may present with upper airway obstruction secondary to obstructive lesions at the upper aerodigestive tract necessitating tracheostomy first before surgical removal of the papillomatous lesions. Social life after tracheostomy has been challenging to sufferers due to some acts of social isolation. Provisional diagnosis may be made based on thorough history taking, physical examination and at times imaging findings; the final diagnosis is based on histopathological analysis of biopsy specimens from the anatomical site involved, collected upon direct laryngoscopy [19]. Findings from the available literatures have been reported invariably and the aim of this paper is thus to give an overview on aetiology, clinical presentation, treatment and outcomes of RRP.

\section{Aetiology, Age at Presentation, Risk Factors and Se- verity Course of Recurrent Respiratory Papillomato- sis (RRP)}

RRP has been reported consistently to be caused by low risk HPV subtypes which are HPV type 6 and 11. Both subtypes are implicated in both Adult and Juvenile onset forms of RRP. HPV is a DNA virus of the Papillomaviridae family and has non-encapsulated, double- chain icosahedric structure, and is composed of 72 capsomeres which are approximately $55 \mathrm{~nm}$ in diameter $[20,21]$. Generally, there are more than 100 subtypes of HPV [4,15,22-24]. Majority of the available studies report the mean age at diagnosis of Juvenile Onset RRP to be 3.8 years while the adult form manifests normally in the 3rd or 4th decade of life and rarely manifests in those older than 60 years of age and the younger the patient's age at diagnosis, the more likely the patient will have severe disease $[1,11,25]$. The disease associated with HPV-11 is more severe and thus as many as about $70 \%$ require tracheostomy compared to $20 \%$ of those children afflicted with HPV-6 [1,3,26,27]. Most patients with RRP caused by HPV-11 runs a severe course of disease and thus may require several surgical interventions [26-29]. Other subtypes, such as $16,18,31$, and 33 , are also associated with RRP, although with reported lower prevalence. Subtypes 16 and 18 are considered to be high risk, with the potential for malignant transformation, particularly to squamous cell carcinoma, which occurs in less than $1 \%$ of juvenile RRP cases [20,30]. With the HPV subtype reported consistently to cause the severe form of RRP, there are other characteristics belonging to the virus such as spread outside the larynx, longer duration of the illness, propensity for malignant transformation especially in adults and the tendency to require high annual number of surgeries and lower age at which the diagnosis is made [31-36].

The Juvenile form of RRP tends to be more aggressive and with numerous papillomatous lesions and high recurrence rate and thus require many surgical interventions during one's life time to maintain airway and thus the risk of voice compromise is commoner with this form $[27,35]$. The cause of Juvenile form is peripartum transmission of the implicated virus and even though vaginal delivery is implicated but caesarian section is also not protective [36-38]. The known classic triad for the increased risk of the Juvenile form include being first born and vaginal delivery by a teenage mother (mother younger than 20 years) of lower socio-economic status. Sexual abuse to children younger than 5 years have also been reported in some occasions [38]. It has been postulated that newborns can acquire RRP from genital HPV infection during passage through an HPV-infected birth canal as a result of transplacental transmission of maternal infection or postnatal contact with an infected individual [8]. The risk is thought to be higher in women with overt anogenital warts or disease from a recent HPV infection at the time of delivery [1]. With the Adult form of RRP, sexual transmission is the most probable risk factor, and this may be linked to increased number of life time sexual partners and more frequent acts of orogenital sex [38]. In this form, the papillomas are often solitary and with a high degree of inflammatory reactivity thus they do not usually spread and recur less frequently than those seen in the juvenile form [30].

\section{Affinity of HPV to Epithelial Surfaces of the Respiratory Tree especially the Larynx}

The virus implicated in RRP has shown predilection to the stratified epithelium belonging either to mucosal or even cutaneous surfaces and upon stem cell infection particularly keratinocyte within the basal layer of the mucosa of the airways tends to induce laryngeal papillomatosis [39]. The typical anatomical location where such process begins is at various anatomical sites where squamous epithelium becomes adjacent to ciliated columnar epithelium at the respiratory tree [40]. Consequent to activation of HPV epidermal growth factor receptor (EGFR) pathway and inactivation of several tumor-suppressor proteins, cellular proliferation and defective epithelial differentiation ensues in affected individuals [39]. As a result of the stated mechanisms directed to the mucosal surface of the respiratory tree, exophytic growths characterizing laryngeal papilloma's develop [5].

\section{Sex Distribution of Recurrent Respiratory Papilloma- tosis}

Available literatures have shown diverse results in terms of sex predilection in RRP. Most studies have concluded Juvenile Onset RRP to affect males and females in equal predominance but the Adult Onset RRP affects males than females [1-4]. A different picture is depicted in the adult form of RRP where males are more affected than females. Whether males are more exposed to orogenital sex than females remain to be still uncertain, but this may be a hypothesis since the adult form may develop from a latent infection which was acquired since childhood.

\section{Clinical Presentation of RRP}

Available studies have reported patients with RRP to have variable clinical features though symptoms of airway involvement 
like progressive hoarseness, stridor, dyspnea, wheezing acute respiratory distress or chronic cough should alarm about the possibility of RRP. Because of non-specific features of RRP, a high index of suspicion is needed whenever a clinician encounter a child presenting with such suggestive symptoms otherwise experience from hospital settings shows misdiagnosis of patients presenting with such complaints where they are diagnosed to have bronchial asthma during their first encounter and others may diagnose them to have laryngotracheobronchitis, acute laryngitis, chronic bronchitis and vocal nodules [7,32,41] and therefore impeding early diagnosis and consequently delaying the act of instituting treatment to such patients. Chest $\mathrm{x}$-ray is usually unreliable, and this is the commonly ordered investigation in children presenting with chronic cough and dyspnea [41]. Such children may go undiagnosed for years especially with the clear chest radiographs.

\section{Treatment Modalities for RRP}

Upon establishing the diagnosis of RRP with the aid of indirect laryngoscopy/direct laryngoscopy and sending the biopsy specimen for histology for the first time when such specimen is taken, then strategies towards minimizing number of annual surgeries should be kept in mind. There are several surgical options which have been practicable in various hospital settings in different parts of the world such as micro laryngeal surgery, microdebriders, angiolytic and carbon dioxide laser. None has been proven to be superior compared to the other [12]. Placement of a tracheotomy tube is the oldest treatment modality for RRP disease. Although generally avoided today, it is occasionally still necessary for advanced disease or stenotic complications [42]. Concern has been raised regarding the role of tracheotomy tubes in potentiating distal spread of RRP [2643].

The carbon dioxide $\left(\mathrm{CO}_{2}\right)$ laser has been a mainstay of treatment for RRP since its introduction to endolaryngeal surgery in the 1970s. Laser energy is absorbed by water in the tissues resulting in ablation, and when coupled with an operating microscope, may result in precise, hemostatic vaporization of papillomas with minimal damage to underlying normal tissues [12].

Adjuvant therapies used for RPP include interferon, cidofovir, indole-3-carbinol, ribavirin and acyclovir. As a rare disease there is a serious lack of large population studies to prove the efficacy of these drugs. Up to now, the most extensively investigated adjuvant therapies are interferon-alpha (1990) and cidofovir (2000) [4]. Subcutaneous interferon was first introduced in 1990 but has been recently replaced by cidofovir due to severe associated drug toxicity $[44,45]$. Cidofovir is a recent antiviral drug, a nucleoside analog, approved by the FDA (Food and Drug Administration) for intravenous use to treat cytomegalovirus retinitis in patients with acquired immunodeficiency syndrome. Although it has not been approved for intralesional administration, cidofovir has been used to treat RPP since 1998, with promising results [4].

Intralesional cidofovir should be started when surgical debulking is required every 2-3 months. Administration should remain below to the established safety limits of dosing ( $3 \mathrm{mg}$ / $\mathrm{kg}$ ) and volume [28,46-51]. Its safety profile has recently been debated because of a possible eventual oncogenic potential but that risk has not been confirmed by recent human studies and it has been recommended for the treatment of moderate to severe RPP [52]. However, high quality data are needed and so informed consent (including discussion of off-label use and acute kidney injury, especially in children), is mandatory. Despite the multiple therapeutic protocols used by physicians, no consistently effective treatment of RRP is available to date. Immunotherapy has also been suggested by other studies as one of the treatment modalities for RRP and it involve administration of Heat shock protein $\mathrm{E} 7$ which is the fusion protein of recombinant heat shock protein 65 from Mycobacterium bovis and the E7 protein from HPV-16. Subcutaneous administration of three doses of heat shock protein E7 after debulking surgery showed significant lengthening of surgical intervals, especially in female patients. This product is not currently commercially available but may have some clinical use in the future.

\section{Possibility of Malignant Transformation of RRP}

Most cases of documented RRP are cytologically benign and rarely undergo malignant transformation; however, squamous cell carcinoma (SCC) can arise from RRP in the absence of identifiable risk factors such as radiation, extraesophageal reflux and smoking and this applies to those with Adult Onset RRPs where such individuals may have exposure to carcinogens during one's life where he/she may be suffering from RRPs too.

Malignant transformation in RRP has been reported but no consensus has been established to date as to what may predispose an individual to with laryngeal papillomatosis to end up with cancer of the larynx. Some studies have analyses molecular component of such individual and concluded the synergistic presence of HPV-11 infection and a mutated p53 tumor suppressor gene might be involved in malignant progression of the RRP [8]. Another study reported malignant transformation of RRP to epidermoid carcinoma and this was observed with HPV-11 and this lies in line with what has been reported in literatures where the HPV-11 subtype is associated with a risk of malignant transformation though it's a low risk subtype [4].

\section{Conclusion}

RRP is relatively a benign disease and has been a subject of concern in clinical practice due to its potential morbidity and mortality both in children and adults. HPV subtypes 6 and 11 were found to be the etiological agents with subtype-11 associated with a risk of malignant transformation among the 
two subtypes. Natural history of RRP has remain to be quite variable and include spontaneous regression, persistence, and dissemination of lesions causing airway compromise and, in rare instances, undergoing malignant transformation to squamous cell carcinoma. Clinicians should have a high index of suspicion when encountering patients with chronic cough, dyspnea and hoarseness of voice since they may be misdiagnosed thus ending up with upper airway obstruction which is potentially fatal. Efforts should be directed towards innovation of curative treatment since no effective curative treatment modality is available to date and thus surgery has remained to be the main stay of treatment. Conclusively, knowledge of etiology, clinical features, treatment modalities of the disease is essential to suggest a correct diagnosis, which must be confirmed by histopathology.

\section{References}

1. Katsenos S, Becker HD (2011) Recurrent respiratory papillomatosis: a rare chronic disease, difficult to treat, with potential to lung cancer transformation: apropos of two cases and a brief literature review. Case reports in oncology 4(1): 162-171.

2. Benavente FM, Contreras M, Perferi G, Azzari C, Muñoz M, et al. (2017) Papilomatosis respiratoria recurrente en paciente pediátrico: reporte de un caso. Revista chilena de pediatría 88(3): 393-397.

3. Armstrong LR, Preston EJ, Reichert M, Phillips DL, Nisenbaum R et al. (2000) Incidence and prevalence of recurrent respiratory papillomatosis among children in Atlanta and Seattle. Clinical Infectious Diseases 31(1): 107-109.

4. Correia S, Dionísio J, da Costa JD (2015) Recurrent respiratory papillomatosis of the airway: The experience of an endoscopic unit Revista Portuguesa de Pneumologia (English Edition) 21(2): 82-89.

5. Kashima H, Leventhal B, Mounts P, Hruban RH (1993) Sites of predilection in recurrent respiratory papillomatosis. Annals of Otology, Rhinology \& Laryngology 102(8): 580-583.

6. Gallagher TQ Derkay CS (2008) Recurrent respiratory papillomatosis: update 2008. Current opinion in otolaryngology \& head and neck surgery 16(6): 536- 542.

7. Goon P, Sonnex C, Jani P, Stanley M, Sudhoff H (2008) Recurrent respiratory papillomatosis: an overview of current thinking and treatment. European Archives of Oto-Rhino-Laryngology 265(2): 147151.

8. Rady PL, Schnadig VJ, Weiss RL, Hughes TK, Tyring SK (1998) Malignant transformation of recurrent respiratory papillomatosis associated with integrated human papillomavirus type 11 DNA and mutation of p53. The Laryngoscope 108(5): 735-740.

9. Sajan JA, Kerschner JE, Merati AL, Osipov V, Szabo S, et al. (2010) Prevalence of dysplasia in juvenile-onset recurrent respiratory papillomatosis. Archives of Otolaryngology-Head \& Neck Surgery 136(1): 7-11.

10. Reeves WC, Ruparelia SS, Swanson KI, Derkay CS, Marcus A, et al. (2003) National registry for juvenile-onset recurrent respiratory papillomatosis. Archives of Otolaryngology-Head \& Neck Surgery 129(9): 976-982.

11. Venkatesan NN, Pine HS, Underbrink MP (2012) Recurrent respiratory papillomatosis. Otolaryngologic Clinics of North America 45(3): 671694.

12. Johnson K, Derkay C (2009) Palliative aspects of recurrent respiratory papillomatosis. Otolaryngologic Clinics of North America 42(1): 57-70.
13. Lieder A, Khan MK, Lippert BM (2014) Photodynamic therapy for recurrent respiratory papillomatosis. Cochrane Database of Systematic Reviews p. 6.

14. Gallagher TQ, Derkay CS (2009) Pharmacotherapy of recurrent respiratory papillomatosis: an expert opinion. Expert opinion on pharmacotherapy 10(4): 645-655.

15. Reidy PM, Dedo HH, Rabah R, Field JB, Mathog RH, et al. (2004) Integration of human papillomavirus type 11 in recurrent respiratory papilloma-associated cancer. The Laryngoscope 114(11): 1906-1909.

16. Gerein V, Rastorguev E, Gerein J, Jecker P, Pfister H (2005) Use of interferon-alpha in recurrent respiratory papillomatosis: 20-year follow-up. Annals of Otology, Rhinology \& Laryngology 114(6): 463471.

17. Nodarse-Cuní H, Iznaga-Marín N, Viera-Alvarez D, Rodríguez-Gómez H, Fernández-Fernández H, et al. (2004) Cuban Group for the Study of Interferon in Recurrent Respiratory Papillomatosis. Interferon alpha$2 \mathrm{~b}$ as adjuvant treatment of recurrent respiratory papillomatosis in Cuba: National Programme (1994-1999 report). The Journal of Laryngology \& Otology 118(9): 681-687.

18. Nam HS, Koh WJ, Suh GY, Chung MP, Kwon OJ, et al. (2008) Efficacy of long-term interferon-alpha therapy in adult patients with recurrent respiratory papillomatosis. Tuberculosis and Respiratory Diseases 65(5): 390-395.

19. Fortes HR, Von Ranke FM, Escuissato DL, Neto CA, Zanetti G, et al. (2017) Recurrent respiratory papillomatosis: A state-of-the-art review. Respiratory medicine 126: 116-121.

20. Fusconi M, Grasso M, Greco A, Gallo A, Campo F, et al. (2014) Recurrent respiratory papillomatosis by HPV: review of the literature and update on the use of cidofovir. Acta Otorhinolaryngologica Italica 34(6): 375.

21. Donne AJ, Hampson L, Homer JJ, Hampson IN (2010) The role of HPV type in recurrent respiratory papillomatosis. International Journal of Pediatric Otorhinolaryngology 74(1): 7-14.

22. Szeps M, Dahlgren L, Aaltonen LM, Öhd J, Kanter-Lewenshon L, et al. (2005) Human papillomavirus, viral load and proliferation rate in recurrent respiratory papillomatosis in response to alpha interferon treatment. Journal of general virology 86(6): 1695-1702.

23. Pignatari S, Smith EM, Shive C, Gray SD, Turek LP (1992) Detection of human papillomavirus infection in diseased and nondiseased sites of the respiratory tract in recurrent respiratory papillomatosis patients by DNA hybridization. Annals of Otology, Rhinology \& Laryngology 101(5): 408-412.

24. Zur Hausen H (2002) Papillomaviruses and cancer: from basic studies to clinical application. Nature reviews cancer 2(5): 342.

25. Gandhi S, Jacob R (2012) Remission in juvenile-onset recurrent respiratory papillomatosis. Journal of Laryngology and Voice 2(1): 30 34.

26. Cole RR, Myer III CM, Cotton RT (1989) Tracheotomy in children with recurrent respiratory papillomatosis. Head \& neck 11(3): 226-230.

27. Silverberg MJ, Thorsen P, Lindeberg H, Ahdieh-Grant L, Shah KV (2004) Clinical course of recurrent respiratory papillomatosis in Danish children. Archives of Otolaryngology-Head \& Neck Surgery 130(6): 711-716.

28. Schraff S, Derkay CS, Burke B, Lawson L (2004) American Society of Pediatric Otolaryngology members' experience with recurrent respiratory papillomatosis and the use of adjuvant therapy. Archives of otolaryngology-head \& neck surgery 130(9): 1039-1042.

29. Ruparelia S, Unger ER, Nisenbaum R, Derkay CS, Reeves WC (2003) Predictors of remission in juvenile-onset recurrent respiratory papillomatosis. Archives of Otolaryngology-Head \& Neck Surgery 129(12): 1275-1278. 
30. Marchiori E, Araujo Neto CD, Meirelles GS, Irion KL, Zanetti G, et al. (2008) Laryngotracheobronchial papillomatosis: findings on computed tomography scans of the chest. Jornal Brasileiro de Pneumologia 34(12): 1084-1089.

31. Long YT, Sani A (2003) Recurrent respiratory papillomatosis. Asian journal of surgery 26(2): 112-116.

32. Stamataki S, Nikolopoulos TP, Korres S, Felekis D, Tzangaroulakis A, et al. (2007) Juvenile recurrent respiratory papillomatosis: still a mystery disease with difficult management. Head \& neck 29(2): 155-162.

33. Derkay CS (1995) Task force on recurrent respiratory papillomas: a preliminary report. Archives of Otolaryngology-Head \& Neck Surgery 121(12): 1386-1391.

34. Armstrong LR, Derkay CS, Reeves WC (1999) Initial results from the national registry for juvenile-onset recurrent respiratory papillomatosis. Archives of Otolaryngology-Head \& Neck Surgery 125(7): 743-748.

35. Larson DA, Derkay CS (2010) Epidemiology of recurrent respiratory papillomatosis. Apmis 118(6-7): 450-454.

36. Reeves WC, Ruparelia SS, Swanson KI, Derkay CS, Marcus A, et al. (2003) National registry for juvenile-onset recurrent respiratory papillomatosis. Archives of Otolaryngology-Head \& Neck Surgery 129(9): 976-982.

37. Niyibizi J, Rodier C, Wassef M, Trottier H (2014) Risk factors for the development and severity of juvenile-onset recurrent respiratory papillomatosis: a systematic review. International journal of pediatric otorhinolaryngology 78(2): 186-197.

38. Ruiz R, Achlatis S, Verma A, Born H, Kapadia F, et al. (2014) Risk factors for adult-onset recurrent respiratory papillomatosis. The Laryngoscope 124(10): 2338-2344.

39. Derkay CS, Wiatrak B (2008) Recurrent respiratory papillomatosis: a review. The Laryngoscope 118(7): 1236-1247.

40. Kashima H, Leventhal B, Mounts P, Hruban RH (1993) Sites of predilection in recurrent respiratory papillomatosis. Annals of Otology, Rhinology \& Laryngology 102(8): 580-583.

41. Xue Q Wang H, Wang J (2010) Recurrent respiratory papillomatosis: an overview. European journal of clinical microbiology \& infectious diseases 29(9): 1051-1054.
42. Perkins JA, Inglis AF, Richardson MA (1998) Iatrogenic airway stenosis with recurrent respiratory papillomatosis. Archives of OtolaryngologyHead \& Neck Surgery 124(3): 281-287.

43. Weiss MD, Kashima HK (1983) Tracheal involvement in laryngeal papillomatosis. The Laryngoscope 93(1): 45-48.

44. Derkay CS, Volsky PG, Rosen CA, Pransky SM, McMurray JS, et al. (2013) Current use of intralesional cidofovir for recurrent respiratory papillomatosis. The Laryngoscope 123(3): 705-712.

45. Schraff S, Derkay CS, Burke B, Lawson L (2004) American Society of Pediatric Otolaryngology members' experience with recurrent respiratory papillomatosis and the use of adjuvant therapy. Archives of otolaryngology-head \& neck surgery 130(9): 1039-1042.

46. Wierzbicka M, Jackowska J, Bartochowska A, Józefiak A, Szyfter W, et al. (2011) Effectiveness of cidofovir intralesional treatment in recurrent respiratory papillomatosis. European Archives of OtoRhino-Laryngology 268(9): 1305-1311.

47. Naiman AN, Abedipour D, Ayari S, Fresnel E, Coulombeau B, et al. (2006) Natural history of adult-onset laryngeal papillomatosis following multiple cidofovir injections. Annals of Otology, Rhinology \& Laryngology 115(3): 175-181.

48. Naiman AN, Ayari S, Nicollas R, Landry G, Colombeau B, et al. (2006) Intermediate-term and long-term results after treatment by cidofovir and excision in juvenile laryngeal papillomatosis. Annals of Otology, Rhinology \& Laryngology 115(9): 667-672.

49. Naiman AN, Ceruse P, Coulombeau B, Froehlich P (2003) Intralesional cidofovir and surgical excision for laryngeal papillomatosis. The Laryngoscope 113(12): 2174-2181.

50. RRP Task Force Practice Guidelines for Management of Children with RRP.

51. Pransky SM, Brewster DF, Magit AE, Kearns DB (2000) Clinical update on 10 children treated with intralesional cidofovir injections for severe recurrent respiratory papillomatosis. Archives of OtolaryngologyHead \& Neck Surgery 126(10): 1239-1243.

52. Soma MA, Albert DM (2008) Cidofovir: to use or not to use? Current opinion in otolaryngology \& head and neck surgery 16(1): 86-90.

\begin{tabular}{l} 
Your next submission with Juniper Publishers \\
will reach you the below assets \\
- Quality Editorial service \\
- Swift Peer Review \\
- Reprints availability \\
- E-prints Service \\
- Manuscript Podcast for convenient understanding \\
- Global attainment for your research \\
- Manuscript accessibility in different formats \\
( Pdf, E-pub, Full Text, Audio) \\
- Unceasing customer service \\
Track the below URL for one-step submission \\
https://juniperpublishers.com/online-submission.php \\
\hline
\end{tabular}

